\title{
Ultrasound-Guided Transbronchial Needle Aspiration
}

National Cancer Institute

\section{Source}

National Cancer Institute. Ultrasound-Guided Transbronchial Needle Aspiration. NCI

Thesaurus. Code C67286.

The use of ultrasound imaging to guide needle aspiration through the bronchial wall. 